\title{
Influence of Bending Vibration on the Vertical Vibration Behaviour of Railway Vehicles Carbody
}

\author{
Mădălina Dumitriu ${ }^{1, *(D)}$ and Ioana Izabela Dihoru ${ }^{2}$ \\ 1 Department of Railway Vehicles, University Politehnica of Bucharest, 060042 București, Romania \\ 2 Doctoral School of Mechanical Engineering and Mechatronics, University Politehnica of Bucharest, \\ 060042 București, Romania; ioana.dihoru@upb.ro \\ * Correspondence: madalina.dumitriu@upb.ro
}

Citation: Dumitriu, M.; Dihoru, I.I. Influence of Bending Vibration on the Vertical Vibration Behaviour of Railway Vehicles Carbody. Appl. Sci. 2021, 11, 8502. https://doi.org/ 10.3390/app11188502

Academic Editor:

Alessandro Gasparetto

Received: 17 August 2021

Accepted: 11 September 2021

Published: 13 September 2021

Publisher's Note: MDPI stays neutral with regard to jurisdictional claims in published maps and institutional affiliations.

Copyright: (C) 2021 by the authors Licensee MDPI, Basel, Switzerland. This article is an open access article distributed under the terms and conditions of the Creative Commons Attribution (CC BY) license (https:/ / creativecommons.org/licenses/by/ $4.0 /)$.

\begin{abstract}
The topic of reducing structural vibrations in the case of flexible carbodies of railway vehicles has been intensively studied, but it is still an active research topic thanks to the importance of the perspective of improving the ride comfort. However, no study has been identified in the specialty literature to feature the contribution of the vibration structural modes upon the vibration behaviour of the railway vehicle carbody. The structural vibration modes of the flexible carbodies are particularly complex; however, the first vertical bending mode holds great significance in terms of the ride comfort. This paper analyses the influence of the first vertical bending mode on the vibration behaviour in three reference points of the railway vehicle carbody in correlation with the carbody flexibility, the vehicle velocity and the suspension damping. This study relies on comparisons between the results of the numerical simulations obtained for a 'flexible carbody' type model of the vehicle and the ones obtained for a 'rigid carbody' type model. The first part of this study analyses the characteristics of the vertical vibrations behaviour of the flexible carbody based on the dynamic response of the vehicle and expressed as the acceleration power spectral density. In the second part, the influence of the vertical bending on the vertical vibrations level of the carbody is analysed using the root mean square of the vertical acceleration.
\end{abstract}

Keywords: railway vehicle; flexible carbody; bending vibration; 'rigid carbody' model; 'flexible carbody' model

\section{Introduction}

The railway vehicle is a complex oscillating system that has vibration behaviour with specific characteristics, which can have unfavourable effects on ride quality, comfort of passengers, cargo integrity and traffic safety. The vibrations of railway vehicles are mainly caused by the geometric deviations of the track and by the irregularities of the rolling surfaces of the rails [1-8]. They come from the construction imperfections, track exploitation and change in the infrastructure due to the action of the environment factors or soil movements [9]. These above, along with the constructive discontinuities of the rail-joints, switches and crossings, represent the major causes of railway vehicle vibration. Wheel defects such as eccentricity, ovality, polygonal profile, corrugation, flat wheel, flattening or the defects of rolling surfaces are also causes of railway vehicle vibration [10-14].

What defines the vibrations in the railway vehicle is that they are low frequency vibrations that occur both vertically and horizontally in the shape of simple vibration modes-rigid modes - and complex vibration modes - structural vibration modes. The construction of the railway vehicle usually complies with the rules of geometric symmetry, inertial and elastic; hence, the vertical vibrations can be regarded as decoupled from the ones in the horizontal vibrations and, for that reason, separately dealt with.

The issue of reducing the vibrations of the railway vehicle is open to research, mainly for the high velocity vehicles. Reducing the weight of the vehicle, in particular the carbody, is one of the basic criteria for the design of high-speed rail vehicles. Reducing the weight 
of the vehicle contributes to increasing speed and reducing energy consumption, ground vibrations and manufacturing costs [15].

The design of the lightweight carbody involves the use of lightweight materials and the modification of mechanical structures. This often leads to a lower structural stiffness of the carbody and therefore to a decrease of the eigenfrequencies. The lighter the vehicle carbody, the greater its flexibility, and this facilitates an easy excitation of the carbody structural vibrations that have a negative effect on the ride comfort [16].

Although the carbody structural vibrations are particularly complex, the first vertical bending mode has the greatest influence on ride comfort. The natural frequency of this mode of vibration is found in the range of $6-12 \mathrm{~Hz}$, where the human body has a deeper sensitivity to the vertical vibrations.

The structural vibrations of flexible carbodies have been the object of research in a large number of studies [15,17-21], and the reduction or control of these vibration so as to improve the ride comfort have been dealt with in numerous research [22-40] that can be grouped as follows: approaches concerning the isolation of vibrations, developed on passive, semi-active and active concepts; and approaches regarding the damping of the carbody vibrations, developed in turn on passive or active concepts [39,40]. Nevertheless, to the best of the authors' knowledge, there is no study that features the contribution of the vibration structural modes upon the vibration behaviour of the railway vehicle carbody. Such study is the subject of this paper, which examines the influence of the first vertical bending mode upon the vibration behaviour of the carbody. To show the impact of the vertical bending upon the carbody vibration behaviour, the results derived from the flexible carbody model and the ones obtained using the rigid carbody model need to be compared. Consequently, the study presented in the paper is based on comparisons between the results from the numerical simulations, developed on two models of a four-axle vehicle with two-stage suspension. In the first model, the carbody is represented by a rigid bodythe rigid carbody' model-and, in the second model, the carbody is represented by a Euler-Bernoulli equivalent beam - the, flexible carbody' model. Both models include an original model of the secondary suspension $[18,24,26]$, which considers both the elements of the vertical suspension and the transmission system of the longitudinal forces between the bogie and the carbody. Via this system, the bogie pitch vibrations are transmitted to the carbody and excite the first vertical bending mode.

The basic characteristics of the vertical vibrations behaviour of flexible carbodies are analysed by means of the dynamic response of the vehicle, expressed as the power spectral density of the vertical acceleration in three reference points of the carbody-at the centre and against the two bogies. These points are considered critical points in terms of the vertical vibrations level of the carbody and of the ride comfort [22,41]. The influence of the vertical bending upon the vertical vibrations level of the carbody is highlighted through the root mean square of acceleration in correlation with the carbody flexibility, velocity and the damping ratio of the vehicle suspension.

\section{Model of the Railway Vehicle}

In this section, the two models of the railway vehicle are presented-the, 'rigid carbody' model and the 'flexible carbody' model. The 'rigid carbody' model is a simple model of the railway vehicle, usually used to study the basic characteristics of the carbody vibrations. The 'flexible carbody' model is used on a regular basis to examine the carbody bending vertical vibrations thanks to the fact that it displays a good agreement between the numerical simulations and the field tests [23].

\subsection{General Model Description}

For the proposed study, a four-axle vehicle with two suspension stages travelling at a constant velocity $V$ on a track with vertical irregularities is considered. The two vehicle models - the 'rigid carbody' model and the 'flexible carbody' model, shown in Figure 1 [42] - have several elements in common. Both models comprise seven bodies 
representing the carbody, the suspended masses of the two bogies and the four axles connected to each other by Kelvin-Voigt type systems, helping to model the two stages of suspension. Both bogies and axles are represented by rigid bodies.
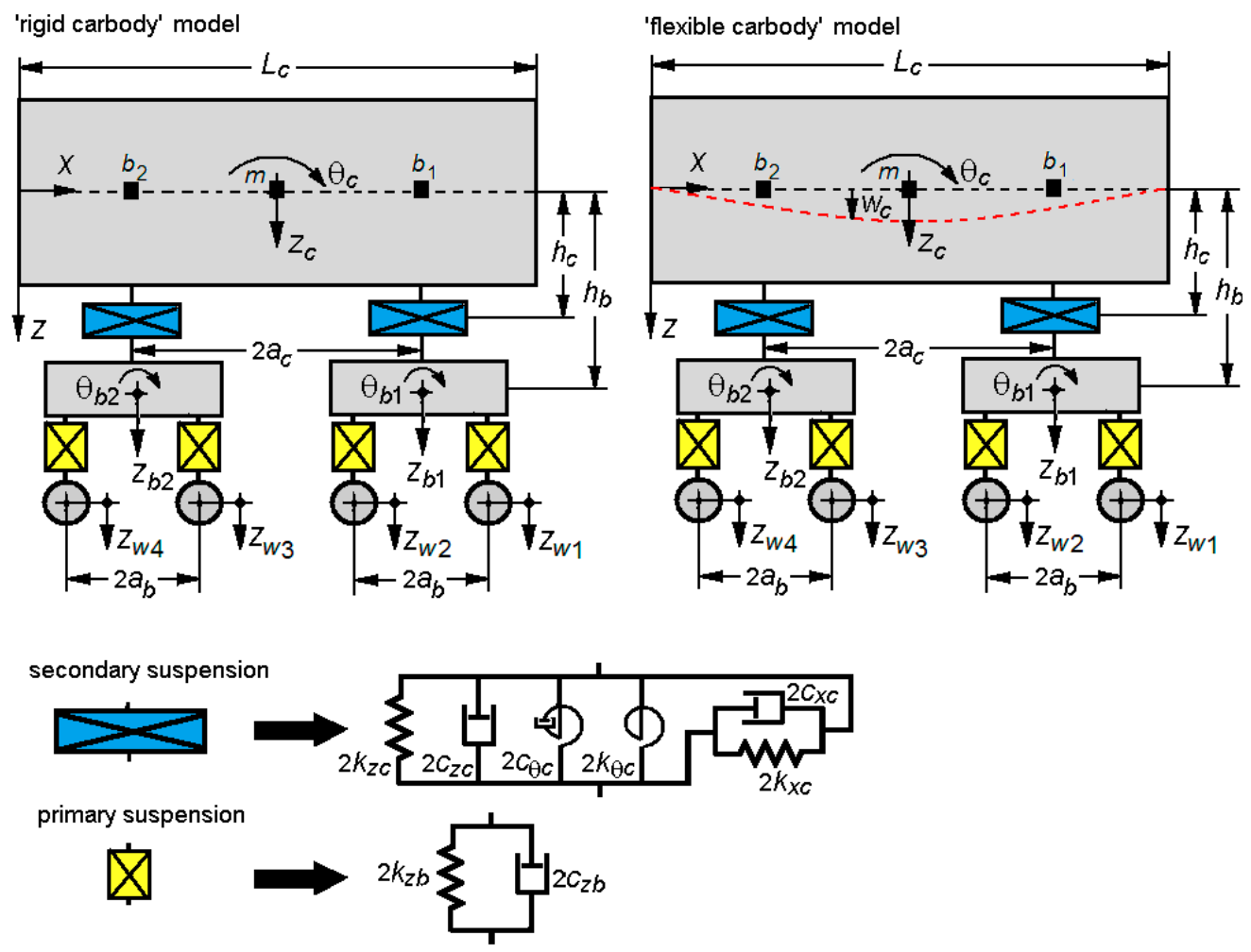

Figure 1. Model of the vehicle: 'rigid carbody' model; 'flexible carbody' model.

The carbody inertia in relation to the rigid vibration modes is described by mass $m_{c}$ and the inertia moment $J_{c}$. The carbody length is $L_{c}$, and the carbody wheelbase is $2 a_{c}$. The rigid vibration modes of the bogies are bounce $z_{b i}$ and pitch $\theta_{b i}$, with $i=1,2$. Each bogie has the mass $m_{b}$ and inertia moment $J_{b}$. The bogie wheelbase is $2 a_{b}$.

Each axle is connected to the bogie chassis through a Kelvin-Voigt system, with the elastic constant $2 k_{z b}$ and the damping constant $2 c_{z b}$. This system models the primary suspension corresponding to an axle.

The bogie is connected to the carbody through the secondary suspension, which is modelled by an assembly consisting of three Kelvin-Voigt systems, of which two are for translation (vertical and longitudinal) and one is for rotation. The Kelvin-Voigt system for longitudinal translation models the transmission system of the longitudinal forces between the carbody and the bogie, and the elements of the Kelvin-Voigt system for rotation take over the relative angular displacement between the carbody and the bogie. The plan of the secondary suspension is located at the distance $h_{c}$ from the medium fiber of the carbody and at the distance $h_{b}$ from the gravity centre of the bogie. The characteristics of the secondary suspension are represented by the elastic constants on the vertical direction $2 k_{z c}$, the longitudinal direction $2 k_{x c}$ and the pitch angular stiffness $2 k_{\theta c}$, as well as the damping constants $2 c_{z c}, 2 c_{x c}$ and $2 c_{\theta c}$.

As for the track model, the rigid track hypothesis is adopted, an approach justified by the fact that the eigenfrequencies of the vertical vibrations of the vehicle carbody considered in this study_-bounce, pitch and vertical bending-are much smaller than the frequencies in the wheelset-track system. The track vertical irregularities impose vertical displacements of the axles, noted with cu $z_{w 1 \ldots 4}$. 


\subsection{The 'Rigid Carbody' Model}

For the 'rigid carbody' model, the vertical vibrations modes in the carbody are bounce $z_{c}$ and pitch $\theta_{c}$, and the motion equations of that describe these movements are of the form

$$
\begin{gathered}
m_{c} \ddot{z}_{c}+2 c_{z c}\left[2 \dot{z}_{c}-\left(\dot{z}_{b 1}+\dot{z}_{b 2}\right)\right]+2 k_{z c}\left[2 z_{c}-\left(z_{b 1}+z_{b 2}\right)\right]=0 \\
J_{c} \ddot{\theta}_{c}+2 c_{z c} a_{c}\left[2 a_{c} \dot{\theta}_{c}-\left(\dot{z}_{b 1}-\dot{z}_{b 2}\right)\right]+2 k_{z c} a_{c}\left[2 a_{c} \theta_{c}-\left(z_{b 1}-z_{b 2}\right)\right]+ \\
+2 c_{x c} h_{c}\left[2 h_{c} \dot{\theta}_{c}+h_{b}\left(\dot{\theta}_{b 1}+\dot{\theta}_{b 2}\right)\right]+2 k_{x c} h_{c}\left[2 h_{c} \theta_{c}+h_{b}\left(\theta_{b 1}+\theta_{b 2}\right)\right]+ \\
\quad+2 c_{\theta c}\left[2 \dot{\theta}_{c}-\left(\dot{\theta}_{b 1}+\dot{\theta}_{b 2}\right)\right]+2 k_{\theta c}\left[2 \theta_{c}-\left(\theta_{b 1}+\theta_{b 2}\right)\right]=0 .
\end{gathered}
$$

The equations of the bounce and pitch motions are as follows:

$$
\begin{gathered}
m_{b} \ddot{z}_{b 1}+2 c_{z b}\left[2 \dot{z}_{b 1}-\left(\dot{z}_{w 1}+\dot{z}_{w 2}\right)\right]+2 k_{z b}\left[2 z_{b 1}-\left(z_{w 1}+z_{w 2}\right)\right]+ \\
+2 c_{z c}\left(\dot{z}_{b 1}-\dot{z}_{c}-a_{c} \dot{\theta}_{c}\right)+2 k_{z c}\left(z_{b 1}-z_{c} \mp a_{c} \theta_{c}\right)=0 \\
m_{b} \ddot{z}_{b 2}+2 c_{z b}\left[2 \dot{z}_{b 2}-\left(\dot{z}_{w 3}+\dot{z}_{w 4}\right)\right]+2 k_{z b}\left[2 z_{b 2}-\left(z_{w 3}+z_{w 4}\right)\right]+ \\
+2 c_{z c}\left(\dot{z}_{b 2}-\dot{z}_{c}+a_{c} \dot{\theta}_{c}\right)+2 k_{z c}\left(z_{b 2}-z_{c}+a_{c} \theta_{c}\right)=0 \\
\ddot{\theta}_{b 1}+2 c_{z b} a_{b}\left[2 a_{b} \dot{\theta}_{b 1}-\left(\dot{z}_{w 1}-\dot{z}_{w 2}\right)\right]+2 k_{z b} a_{b}\left[2 a_{b} \theta_{b 1}-\left(z_{w 1}-z_{w 2}\right)\right]+ \\
+2 c_{x c} h_{b}\left(h_{b} \dot{\theta}_{b 1}+h_{c} \dot{\theta}_{c}\right)+2 k_{x c} h_{b}\left(h_{b} \theta_{b 1}+h_{c} \theta_{c}\right)+2 c_{\theta c}\left(\dot{\theta}_{b 1}-\dot{\theta}_{c}\right)+2 k_{\theta c}\left(\theta_{b 1}-\theta_{c}\right)=0 . \\
J_{b} \ddot{\theta}_{b 2}+2 c_{z b} a_{b}\left[2 a_{b} \dot{\theta}_{b 2}-\left(\dot{z}_{w 33}-\dot{z}_{w w 4}\right)\right]+2 k_{z b} a_{b}\left[2 a_{b} \theta_{b 2}-\left(z_{w w 3}-z_{w 4}\right)\right]+ \\
+2 c_{x c} h_{b}\left(h_{b} \dot{\theta}_{b 2}+h_{c} \dot{\theta}_{c}\right)+2 k_{x c} h_{b}\left(h_{b} \theta_{b 2}+h_{c} \theta_{c}\right)+2 c_{\theta c}\left(\dot{\theta}_{b 2}-\dot{\theta}_{c}\right)+2 k_{\theta c}\left(\theta_{b 2}-\theta_{c}\right)=0 .
\end{gathered}
$$

\subsection{The 'Flexible Carbody' Model}

In the case of the 'flexible carbody' model, the vehicle carbody is represented by a free-free equivalent beam, with a constant section and uniformly distributed mass, EulerBernoulli type. This model allows for the consideration of the vertical bending modes of the carbody.

The beam parameters are: $\rho_{c}=m_{c} / L$-beam mass per length unit; $\mu$-coefficient of structural damping; and $E I$-bending modulus, where $E$ is longitudinal elastic modulus and $I$ is the moment of inertia in the beam cross-section.

The carbody vibration modes are bounce $z_{c}$, pitch $\theta_{c}$ and the first vertical bending mode. The carbody displacement $w_{c}(x, t)$ comes from the overlap of these three vibration modes of the carbody,

$$
w_{\mathcal{c}}(x, t)=z_{\mathcal{c}}(t)+\left(x-\frac{L_{c}}{2}\right) \theta_{c}(t)+X_{\mathcal{c}}(x) T_{\mathcal{c}}(t),
$$

where $T_{c}(t)$ is the coordinate of the carbody vertical bending and $X_{c}(x)$ its eigenfunction

$$
X_{c}(x)=\sin \beta x+\sinh \beta x-\frac{\sin \beta L-\sinh \beta L}{\cos \beta L-\cosh \beta L}(\cos \beta x+\cosh \beta x),
$$

with

$$
\beta=\sqrt[4]{\omega_{c}^{2} \rho_{c} /(E I)} \text { and } \cos \beta L_{c} \cosh \beta L_{c}-1=0,
$$

where $\omega_{c}$ is the natural angular frequency of the carbody vertical bending.

The vertical motions of the vehicle are described by the equations of the rigid vibration modes of the carbody and bogies—-bounce and pitch — as well as by the equation of the carbody vertical bending.

The carbody motion equation has the general form

$$
E I \frac{\partial^{4} w_{c}(x, t)}{\partial x^{4}}+\mu I \frac{\partial^{5} w_{c}(x, t)}{\partial x^{4} \partial t}+\rho_{c} \frac{\partial^{2} w_{c}(x, t)}{\partial t^{2}}=\sum_{i=1}^{2} F_{z c i} \delta\left(x-l_{i}\right)+\sum_{i=1}^{2}\left(M_{c i}-h_{c} F_{x c i}\right) \frac{\mathrm{d} \delta\left(x-l_{i}\right)}{\mathrm{d} x}
$$


where $\delta($.$) is Dirac's delta function, distances l_{i}$ define the position of the carbody support points on the secondary suspension and $F_{z c i}, F_{x c i}$ and $M_{c i}$ are the forces and the moments, respectively, due to the secondary suspension of the bogie $i$

$$
\begin{gathered}
F_{z c i}=-2 c_{z c}\left(\frac{\partial w_{c}\left(l_{i}, t\right)}{\partial t}-\dot{z}_{b i}\right)-2 k_{z c}\left[w_{c}\left(l_{i}, t\right)-z_{b i}\right] \\
F_{x c i}=2 c_{x c}\left(h_{c} \frac{\partial^{2} w_{c}\left(l_{i}, t\right)}{\partial x \partial t}+h_{b} \dot{\theta}_{b i}\right)+2 k_{x c}\left(h_{c} \frac{\partial w_{c}\left(l_{i}, t\right)}{\partial x}+h_{b} \theta_{b i}\right) \\
M_{c i}=-2 c_{\theta c}\left(\frac{\partial^{2} w_{c}\left(l_{i}, t\right)}{\partial x \partial t}-\dot{\theta}_{b i}\right)-2 k_{\theta c}\left[\frac{\partial w_{c}\left(l_{i}, t\right)}{\partial x}-\theta_{b i}\right]
\end{gathered}
$$

With the help of the modal analysis method and considering the orthogonality property of the eigenfunction of the carbody vertical bending, the motion Equation (8) is transformed into three second order differential equations with ordinary derivatives, describing the three vibration modes of the carbody-bounce, pitch and the vertical bending.

$$
\begin{gathered}
m_{c} \ddot{z}_{c}=\sum_{i=1}^{2} F_{z c i} \\
J_{c} \ddot{\theta}_{c}=\sum_{i=1}^{2} F_{z c i}\left(l_{i}-\frac{L_{c}}{2}\right)-\sum_{i=1}^{2}\left(M_{c i}-h_{c} F_{x c i}\right) \\
m_{m c} \ddot{T}_{c}+c_{m c} \dot{T}_{c}+k_{m c} T_{c}=\sum_{i=1}^{2} F_{z c i} X_{c}\left(l_{i}\right)+\sum_{i=1}^{2}\left(M_{c i}-h_{c} F_{x c i}\right) \frac{\mathrm{d} X_{c}\left(l_{i}\right)}{\mathrm{d} x}
\end{gathered}
$$

In Equation (16) the carbody modal mass is noted with $m_{m c}$, the carbody modal damping with $c_{m c}$ and the carbody modal stiffness with $k_{m c}$, as they are defined as follows:

$$
m_{m c}=\rho_{c} \int_{0}^{L} X_{c}^{2} \mathrm{~d} x, c_{m c}=\mu I \int_{0}^{L}\left(\frac{\mathrm{d}^{2} X_{c}}{\mathrm{~d} x^{2}}\right)^{2} \mathrm{~d} x, k_{m c}=E I \int_{0}^{L}\left(\frac{\mathrm{d}^{2} X_{c}}{\mathrm{~d} x^{2}}\right)^{2} \mathrm{~d} x .
$$

Based on the symmetry properties of the eigenfunction $X_{c}(x)$, the following notations are introduced:

$$
\begin{gathered}
X_{c}\left(l_{1}\right)=X_{c}\left(l_{2}\right)=\varepsilon, \\
\frac{\mathrm{d} X_{c}\left(l_{1}\right)}{\mathrm{d} x}=-\frac{\mathrm{d} X_{\mathcal{c}}\left(l_{2}\right)}{\mathrm{d} x}=\lambda .
\end{gathered}
$$

After replacing (9)-(11) in the carbody motion Equations (14)-(16), in which the notations (18) and (19) are inserted, the carbody motion equations are brought to the following form:

$$
\begin{aligned}
& m_{c} \ddot{z}_{c}+2 c_{z c}\left[2 \dot{z}_{c}+2 \varepsilon \dot{T}_{c}-\left(\dot{z}_{b 1}+\dot{z}_{b 2}\right)\right]+2 k_{z c}\left[2 z_{c}+2 \varepsilon T_{c}-\left(z_{b 1}+z_{b 2}\right)\right]=0 \\
& J_{c} \ddot{\theta}_{c}+2 c_{z c} a_{c}\left[2 a_{c} \dot{\theta}_{c}-\left(\dot{z}_{b 1}-\dot{z}_{b 2}\right)\right]+2 k_{z c} a_{c}\left[2 a_{c} \theta_{c}-\left(z_{b 1}-z_{b 2}\right)\right]+ \\
& +2 c_{x c} h_{c}\left[2 h_{c} \dot{\theta}_{c}+h_{b}\left(\dot{\theta}_{b 1}+\dot{\theta}_{b 2}\right)\right]+2 k_{x c} h_{c}\left[2 h_{c} \theta_{c}+h_{b}\left(\theta_{b 1}+\theta_{b 2}\right)\right]+ \\
& \quad+2 c_{\theta c}\left[2 \dot{\theta}_{c}-\left(\dot{\theta}_{b 1}+\dot{\theta}_{b 2}\right)\right]+2 k_{\theta c}\left[2 \theta_{c}-\left(\theta_{b 1}+\theta_{b 2}\right)\right]=0 \\
& m_{m c} \ddot{T}_{c}+c_{m c} \dot{T}_{c}+k_{m c} T_{c}+ \\
& +2 c_{z c} \varepsilon\left[2 \dot{z}_{c}+2 \varepsilon \dot{T}_{c}-\left(\dot{z}_{b 1}+\dot{z}_{b 2}\right)\right]+2 k_{z c} \varepsilon\left[2 z_{c}+2 \varepsilon T_{c}-\left(z_{b 1}+z_{b 2}\right)\right]+ \\
& +2 c_{x c} h_{c} \lambda\left[2 h_{c} \lambda \dot{T}_{c}+h_{b}\left(\dot{\theta}_{b 1}-\dot{\theta}_{b 2}\right)\right]+2 k_{x c} h_{c} \lambda\left[2 h_{c} \lambda T_{c}+h_{b 2}\left(\theta_{b 1}-\theta_{b 2}\right)\right]+ \\
& +2 c_{\theta c} \lambda\left[2 \lambda \dot{T}_{c}-\left(\dot{\theta}_{b 1}-\dot{\theta}_{b 2}\right)\right]+2 k_{\theta c} \lambda\left[2 \lambda T_{c}-\left(\theta_{b 1}-\theta_{b 2}\right)\right]=0
\end{aligned}
$$


For this model, the bounce and pitch equations of the bogies are as follows:

$$
\begin{gathered}
m_{b} \ddot{z}_{b 1}+2 c_{z b}\left[2 \dot{z}_{b 1}-\left(\dot{z}_{w 1}+\dot{z}_{w 2}\right)\right]+2 k_{z b}\left[2 z_{b i}-\left(z_{w 1}+z_{w 2}\right)\right]+ \\
+2 c_{z c}\left(\dot{z}_{b 1}-\dot{z}_{c}-a_{c} \dot{\theta}_{c}-\varepsilon \dot{T}_{c}\right)+2 k_{z c}\left(z_{b 1}-z_{c}-a_{c} \theta_{c}-\varepsilon T_{c}\right)=0 \\
m_{b} \ddot{z}_{b 2}+2 c_{z b}\left[2 \dot{z}_{b i}-\left(\dot{z}_{w 3}+\dot{z}_{w 4}\right)\right]+2 k_{z b}\left[2 z_{b 2}-\left(z_{w 3}+z_{w 4}\right)\right]+ \\
+2 c_{z c}\left(\dot{z}_{b 2}-\dot{z}_{c}+a_{c} \dot{\theta}_{c}-\varepsilon \dot{T}_{c}\right)+2 k_{z c}\left(z_{b 2}-z_{c}+a_{c} \theta_{c}-\varepsilon T_{c}\right)=0 \\
J_{b} \ddot{\theta}_{b 1}+2 c_{z b} a_{b}\left[2 a_{b} \dot{\theta}_{b 1}-\left(\dot{z}_{w 1}-\dot{z}_{w 2}\right)\right]+2 k_{z b} a_{b}\left[2 a_{b} \theta_{b 1}-\left(z_{w 1}-z_{w 2}\right)\right]+ \\
+2 c_{x c} h_{b}\left[h_{b} \dot{\theta}_{b 1}+h_{c}\left(\dot{\theta}_{c}+\lambda \dot{T}_{c}\right)\right]+2 k_{x c} h_{b}\left[h_{b} \theta_{b 1}+h_{c}\left(\theta_{c}+\lambda T_{c}\right)\right]+ \\
+2 c_{\theta c}\left(\dot{\theta}_{b 1}-\dot{\theta}_{c}-\lambda \dot{T}_{c}\right)+2 k_{\theta c}\left(\theta_{b 1}-\theta_{c}-\lambda T_{c}\right)=0 \\
J_{b} \ddot{\theta}_{b 2}+2 c_{z b} a_{b}\left[2 a_{b} \dot{\theta}_{b 2}-\left(\dot{z}_{w 3}-\dot{z}_{w 4}\right)\right]+2 k_{z b} a_{b}\left[2 a_{b} \theta_{b 2}-\left(z_{w 3}-z_{w 4}\right)\right]+ \\
+2 c_{x c} h_{b}\left[h_{b} \dot{\theta}_{b 2}+h_{c}\left(\dot{\theta}_{c}-\lambda \dot{T}_{c}\right)\right]+2 k_{x c} h_{b}\left[h_{b} \theta_{b 2}+h_{c}\left(\theta_{c}-\lambda T_{c}\right)\right]+ \\
+2 c_{\theta c}\left(\dot{\theta}_{b 2}-\dot{\theta}_{c}+\lambda \dot{T}_{c}\right)+2 k_{\theta c}\left(\theta_{b 2}-\theta_{c}+\lambda T_{c}\right)=0
\end{gathered}
$$

\section{The Dynamic Response of the Railway Vehicle to the Track Vertical Irregularities}

To analyse the vertical vibrations behaviour of the vehicle carbody, we utilised the power spectral density of acceleration in three important points considered critical points of the vibrations level of the carbody and the ride comfort in the railway vehicles [22,41]. These reference points are marked in Figure 1 and found at the centre of the carbody-point $m$-and against the support points of the carbody onto the secondary suspension, above the bogie 1 -point $b_{1}$-and above the bogie 2 -point $b_{2}$.

To calculate the power spectral density of the vertical acceleration of the carbody, the track vertical irregularities are considered to represent a stochastic stationary process, which can be described via the power spectral density. For the average statistical properties of the European railways, the theoretical curve of the power spectral density described by the relation [43]

$$
S(\Omega)=\frac{A \Omega_{c}^{2}}{\left(\Omega^{2}+\Omega_{r}^{2}\right)\left(\Omega^{2}+\Omega_{c}^{2}\right)},
$$

is considered representative, where $\Omega$ is the wavenumber, $\Omega_{c}=0.8246 \mathrm{rad} / \mathrm{m}$, $\Omega_{r}=0.0206 \mathrm{rad} / \mathrm{m}$ and $A$ is a constant depending on the track quality. For a high-quality track, $A=2.119 \times 10^{-7} \mathrm{radm}$, and $A$ is $6.124 \times 10^{-7}$ radm for a low-quality track.

As a function of the angular frequency $\omega=V \Omega$, the power spectral density of the track irregularities can be expressed as in the general equation

$$
G(\omega)=\frac{A \Omega_{c}^{2} V^{3}}{\left[\omega^{2}+\left(V \Omega_{c}\right)^{2}\right]\left[\omega^{2}+\left(V \Omega_{r}\right)^{2}\right]} .
$$

The power spectral density of the carbody vertical acceleration $G_{c}(\omega)$ is calculated differently for the two models of the vehicle, starting from the power spectral density of the track vertical irregularities $G(\omega)$ and from the response functions corresponding to the vibration modes of the carbody-bounce and pitch $\bar{H}_{z_{c}}(\omega), \bar{H}_{\theta_{c}}(\omega)$-and the vertical bending $\bar{H}_{T_{c}}(\omega)$.

In the point $m$ located at the centre of the carbody, the power spectral density of the acceleration is calculated with the following equations:

- $\quad$ for the, rigid carbody' model,

$$
G_{c m}(\omega)=G(\omega)\left|\omega^{2} \bar{H}_{z c}(\omega)\right|^{2}
$$

- for the, flexible carbody' model,

$$
G_{c m}(\omega)=G(\omega)\left|\omega^{2}\left[\bar{H}_{z c}(\omega)+X_{c}\left(\frac{L_{c}}{2}\right) \bar{H}_{T_{c}}(\omega)\right]\right|^{2} .
$$


In the points $b_{1}$ and $b_{2}$, located against the two bogies, the power spectral density of the vertical acceleration is given by the equations below:

- for the, rigid carbody' model,

$$
G_{c b 1,2}(\omega)=G(\omega) \mid \omega^{2}\left[\bar{H}_{z_{c}}(\omega) \pm\left. a_{c} \bar{H}_{\theta_{c}}(\omega]\right|^{2} .\right.
$$

- for the, flexible carbody' model,

$$
G_{c b 1,2}(\omega)=G(\omega)\left|\omega^{2}\left[\bar{H}_{z_{c}}(\omega) \pm a_{c} \bar{H}_{\theta_{c}}(\omega)+X_{c}\left(l_{1,2}\right) \bar{H}_{T_{c}}(\omega)\right]\right|^{2} .
$$

To study the influence of the vertical bending upon the level of vertical vibrations in the vehicle carbody, the root mean square of the vertical acceleration in the three reference points of the carbody will be utilised. This is calculated based on the dynamic response of the vehicle expressed in the form of the power spectral density of the carbody acceleration

- at the centre of the carbody,

$$
a_{c m}=\sqrt{\frac{1}{\pi} \int_{0}^{\infty} G_{c m}(\omega) \mathrm{d} \omega}
$$

- $\quad$ above the two bogies,

$$
a_{c b 1,2}=\sqrt{\frac{1}{\pi} \int_{0}^{\infty} G_{c b 1,2}(\omega) \mathrm{d} \omega .}
$$

\section{Results and Discussion}

This section analyses the influence of the vertical bending upon the vertical vibrations behaviour of the railway vehicle carbody using the results from the numerical simulations developed based on the two previously presented models - the 'rigid carbody' model and the 'flexible carbody' model. The basic characteristics of the vibration behaviour of the vehicle carbody are analysed using the power spectral density of the vertical acceleration in the reference points of the carbody - at the centre of the carbody and against the two bogies. The influence of the vertical bending upon the vertical vibrations level in the reference points of the carbody are analysed based on the root mean square of the vertical acceleration, in correlation with the velocity and damping ratio of the vehicle suspension, for four values of the flexibility of the carbody, corresponding to the bending frequencies of $6 \mathrm{~Hz}, 8 \mathrm{~Hz}, 10 \mathrm{~Hz}$ and $12 \mathrm{~Hz}$.

The reference parameters of the vehicle model used in the numerical simulations are shown in Table 1. The eigenfrequencies of the vertical vibration modes of the carbody corresponding to the reference parameters of the model are the bounce eigenfrequency $f_{b}=1.17 \mathrm{~Hz}$, pitch eigenfrequency $f_{p}=1.46 \mathrm{~Hz}$ and vertical bending eigenfrequency $f_{v b}=8 \mathrm{~Hz}$. It is considered that the vehicle is running on a low-quality track characterised by the coefficient $A=1.080 \times 10^{-6} \mathrm{radm}$.

For the reference parameters of the 'flexible carbody' model, the diagrams in Figure 2 show the power spectral density of the vertical acceleration in the reference points of the carbody, depending on the velocity. The bending vibration is observed as mainly affecting the vibration behaviour at the carbody centre (diagram a) and less above the two bogies (diagrams b and c). At the centre carbody, the power spectral density of the acceleration is dominated by the bounce vibration (at $1.17 \mathrm{~Hz}$ ), but the contribution of the bending vibration (at $8 \mathrm{~Hz}$ ) is also noticeable at high velocities. In the reference points above the bogies, the vibration behaviour of the carbody is dominated by the pitch vibration (at $1.46 \mathrm{~Hz}$ ), whereas the bending weight is not significant. 
Table 1. Reference parameters of the vehicle model.

\begin{tabular}{|c|c|c|c|}
\hline Symbol & Definition & Symbol & Definition \\
\hline \multicolumn{4}{|c|}{ Joint parameters for the 'rigid carbody' model and the 'flexible carbody' model } \\
\hline \multicolumn{4}{|c|}{ The parameters of the carbody and bogie } \\
\hline$m_{c}=34,000 \mathrm{~kg}$ & carbody mass & $L_{c}=26.4 \mathrm{~m}$ & carbody length \\
\hline$m_{b}=3200 \mathrm{~kg}$ & bogie suspended mass & $2 a_{b}=19 \mathrm{~m}$ & carbody wheelbase \\
\hline$J_{c}=1,963,840 \mathrm{~kg} \cdot \mathrm{m}^{2}$ & carbody inertia moment & $2 a_{b}=2.56 \mathrm{~m}$ & bogie wheelbase \\
\hline$J_{b}=2048 \mathrm{~kg} \cdot \mathrm{m}^{2}$ & bogie inertia moment & $h_{c}=1.3 \mathrm{~m} h_{b}=0.2 \mathrm{~m}$ & $\begin{array}{c}\text { elevations of the secondary } \\
\text { suspension plane }\end{array}$ \\
\hline \multicolumn{4}{|c|}{ The parameters of the secondary suspension per bogie } \\
\hline $2 c_{z c}=34.28 \mathrm{kNs} / \mathrm{m}$ & vertical damping & $2 k_{z c}=1.2 \mathrm{MN} / \mathrm{m}$ & vertical stiffness \\
\hline $2 c_{x c}=50 \mathrm{kNs} / \mathrm{m}$ & longitudinal damping & $2 k_{x c}=4 \mathrm{MN} / \mathrm{m}$ & longitudinal stiffness \\
\hline $2 c_{\theta \mathrm{c}}=2 \mathrm{kNm}$ & angular damping & $2 k_{\theta \mathrm{c}}=256 \mathrm{kN} / \mathrm{m}$ & angular stiffness \\
\hline \multicolumn{4}{|c|}{ The parameters of the primary suspension per wheelset } \\
\hline $4 c_{z b}=52.21 \mathrm{kNs} / \mathrm{m}$ & vertical damping & $4 k_{z b}=4.4 \mathrm{MN} / \mathrm{m}$ & vertical stiffness \\
\hline \multicolumn{4}{|c|}{ Parameters specific to the 'flexible carbody' model } \\
\hline$E I=3.158 \times 10^{9} \mathrm{Nm}^{2}$ & bending modulus & $c_{m c}=53.117 \mathrm{kNm} / \mathrm{s}$ & carbody modal damping \\
\hline$m_{m c}=35,224 \mathrm{~kg}$ & carbody modal mass & $k_{m c}=88.998 \mathrm{MN} / \mathrm{m}$ & carbody modal stiffness \\
\hline
\end{tabular}
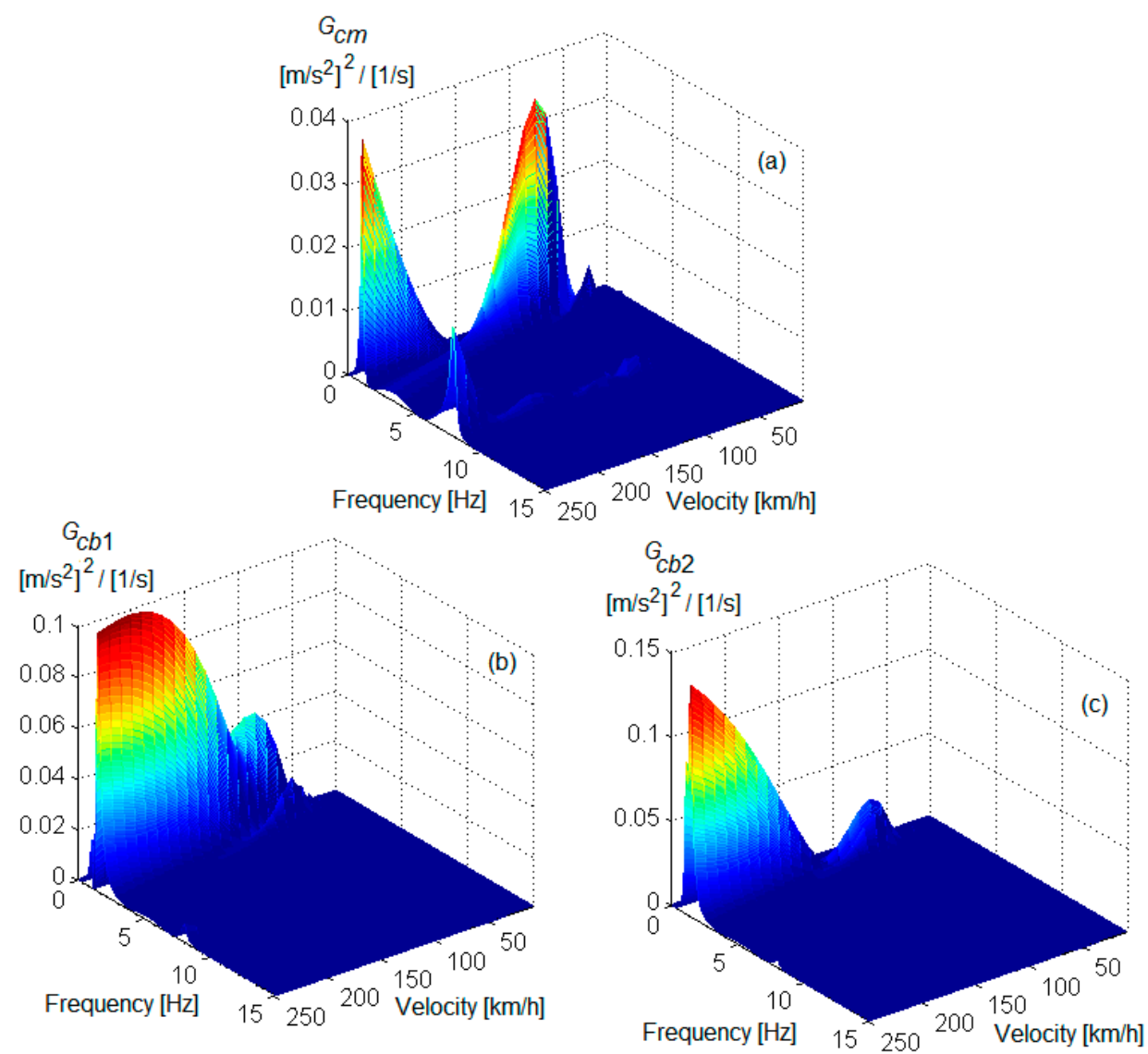

Figure 2. The power spectral density of the carbody acceleration: (a) at the carbody centre; (b) against the front bogie; (c) against the rear bogie. 
To evaluate the influence of the vertical bending upon the of the vertical vibration behaviour of the carbody, the diagrams in Figure 3 are utilised, showing the power spectral density of the vertical acceleration at the velocity of $180 \mathrm{~km} / \mathrm{h}$ for both the 'rigid carbody' model and the 'flexible carbody' model. For the 'flexible carbody' model, four values of the carbody bending frequency were considered, namely $6 \mathrm{~Hz}, 8 \mathrm{~Hz}, 10 \mathrm{~Hz}$ and $12 \mathrm{~Hz}$. What can be noticed in the diagrams are the peaks for the four resonance frequency of bending and the ones corresponding to the vibration rigid modes-the resonance frequency of the carbody bounce and the resonance frequency of the carbody pitch. Apart from these resonance peaks, a series of anti-resonance frequencies can be identified due to the geometric filtering effect [21,44-47].

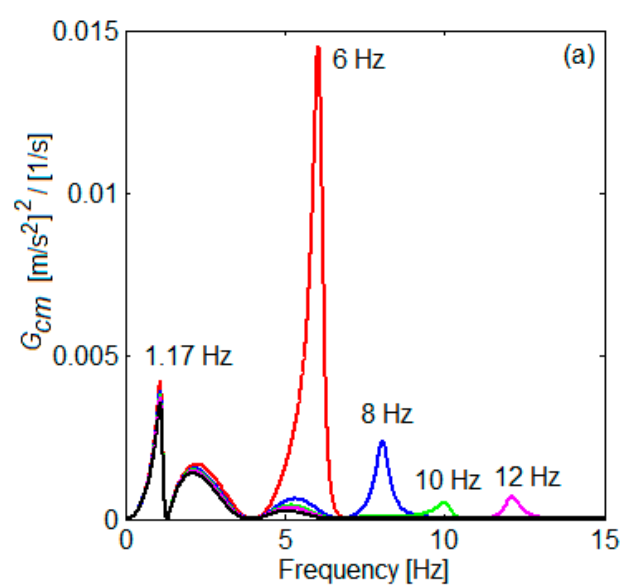

rigid carbody model

flexible carbody model

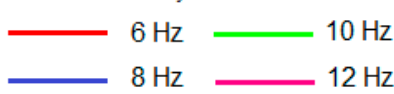

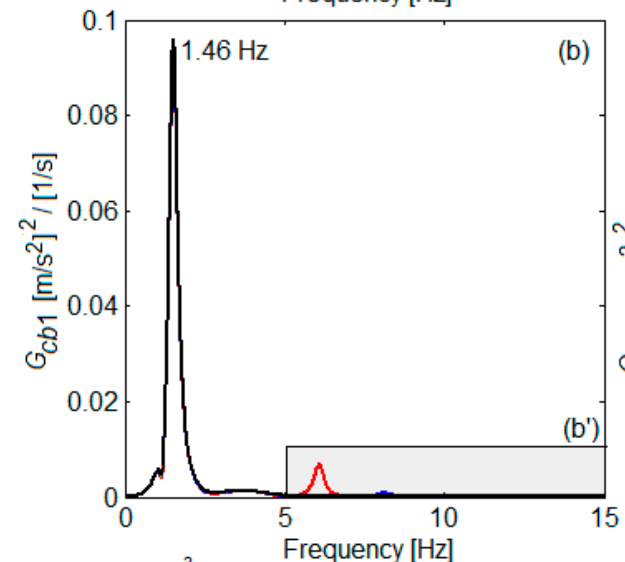
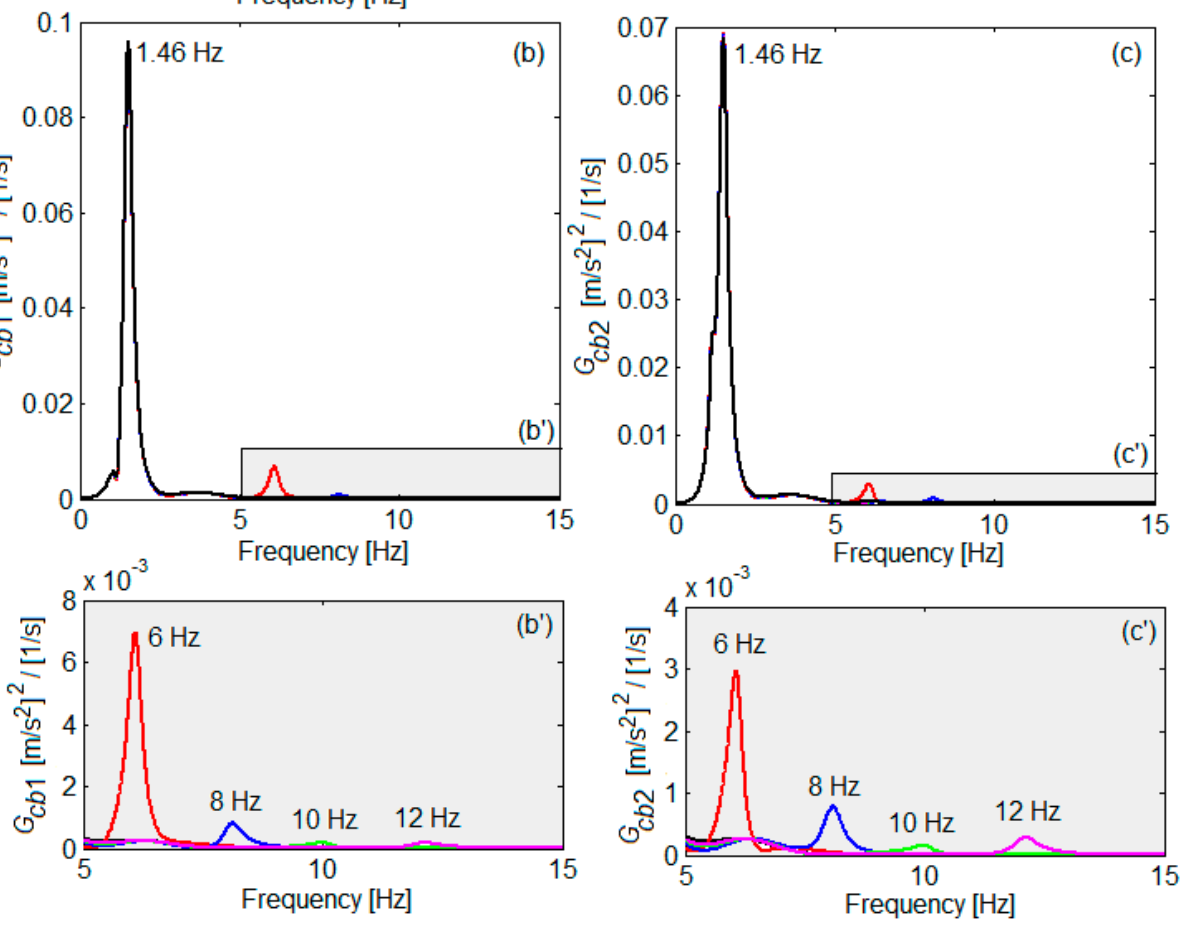

Figure 3. Influence of the vertical bending upon the power spectral density of the carbody acceleration: (a) at the carbody centre; (b) against the front bogie; (c) against the rear bogie.

As shown in Figure 2, the bending vibration is visibly influencing the vibration behaviour of the carbody, mainly at its centre (diagram a) and less above the two bogies (diagrams $b$ and $c$ ). The contribution of the bending vibration is all the more important as the carbody flexibility is higher, which can be clearly noticed at the carbody centre, where the spectrum of the power density of the acceleration is dominated by the bending vibration of the carbody at the frequency of $6 \mathrm{~Hz}$. The more the bending vibration frequency 
increases, the less important the weight of this vibration mode is, the dominant vibration mode being the bounce in the reference points of the carbody above the bogies and the spectrum of the power density of the accelerations dominated by the pitch vibration, both for the 'rigid carbody' and for the 'flexible carbody' models. In these points, the bending weight is very low (see diagrams $\left(b^{\prime}\right)$ and $\left(c^{\prime}\right)$ ), irrespective of the frequency of this vibration mode.

Based on the diagrams in Figure 4, the influence of the vertical bending upon the level of vertical vibrations in the carbody reference points in correlation with velocity is analysed. This analysis is performed by comparing the values of the root mean square of acceleration for the 'flexible carbody' model with those corresponding to the 'rigid carbody' model. The vertical bending causes the increase of the level of vibrations at the centre of carbody, with this increase being important under certain conditions-high flexibility of the carbody and high velocities (diagram a). This is visible in Figure 5, which features the percentage growth of the root mean square of acceleration for the 'flexible carbody' model versus the 'rigid carbody' model. As an example, the root mean square of acceleration for the flexible carbody goes up by $93.6 \%$ for $f_{v b}=6 \mathrm{~Hz}$ at a velocity of $200 \mathrm{~km} / \mathrm{h}$ compared to the root mean square of acceleration for the rigid carbody. For higher values of the carbody bending frequency, the increase in the root mean square of acceleration does not exceed $20 \%$. As seen in the diagrams (b) and (c), the carbody vertical bending does not sensibly affect the level of vibrations above the bogies, which is valid irrespective of the carbody bending frequency.
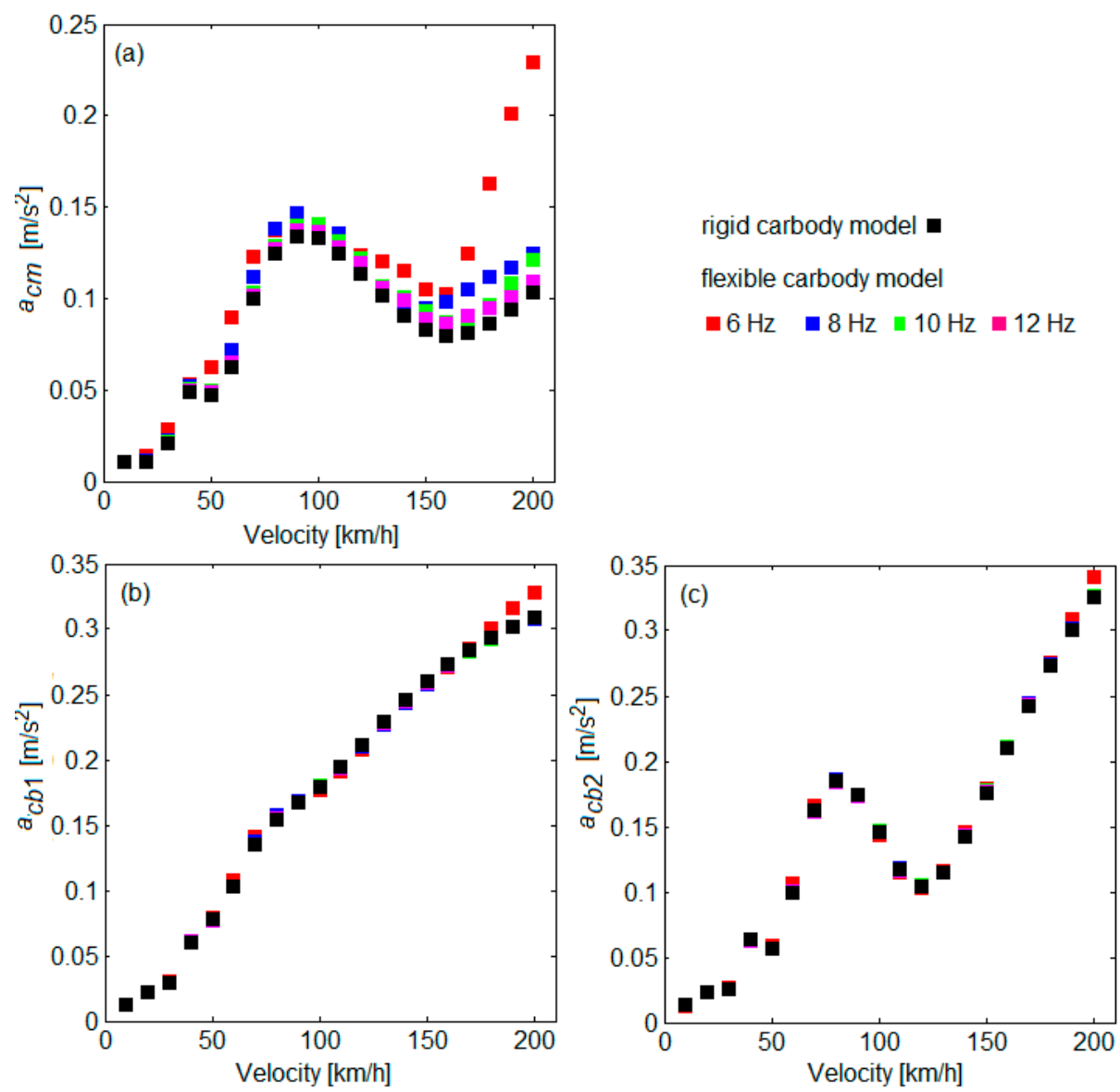

Figure 4. Influence of the carbody vertical bending upon the root mean square of acceleration in correlation with the velocity: (a) at the carbody centre; (b) against the front bogie; (c) against the rear bogie. 


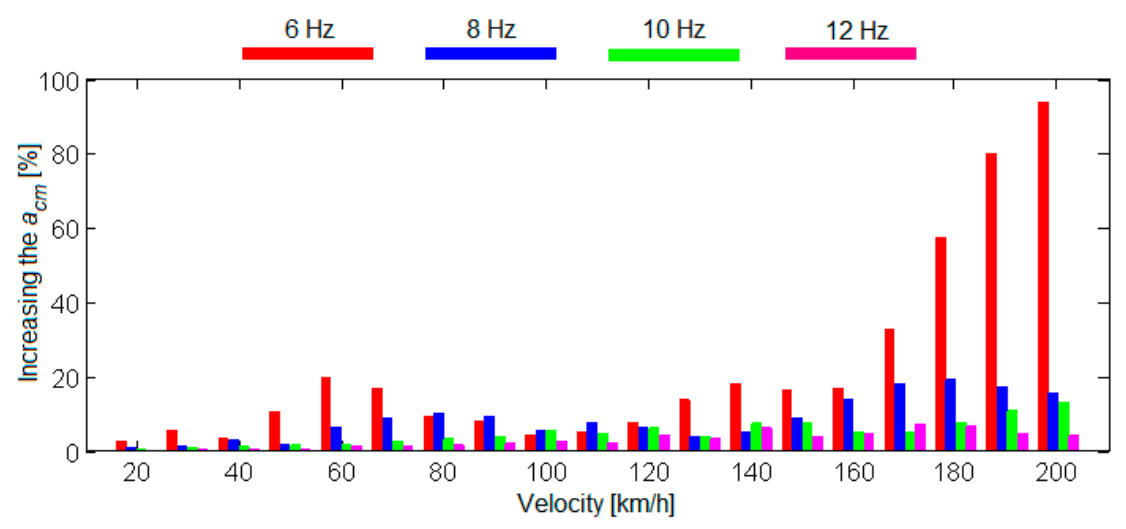

Figure 5. Increase of root mean square of acceleration at the carbody centre versus the rigid carbody.

Another interesting aspect to be analysed is related to the manner in which the vertical bending changes the position of the point where the vibrations level is the highest, hereafter called the critical point of the carbody. This can be done based on the diagrams in Figure 6, which show the root mean square of acceleration in the reference points of the rigid carbody (diagram a) and the root mean square of acceleration in the reference points of the flexible carbody for $f_{v b}=6 \mathrm{~Hz}$ (diagram $\mathrm{b}$ ). It is observed that the bending vibration does not change the position of the carbody critical point. For both models, the carbody critical point is located above one of the two bogies, and its position changes as a function of velocity. At velocities smaller than $92 \mathrm{~km} / \mathrm{h}$, the carbody critical points alternate either above the rear bogie or the front bogie. A large velocity interval follows afterwards, which extends up to $190 \mathrm{~km} / \mathrm{h}$, where the carbody critical point is the reference point situated above the front bogie.
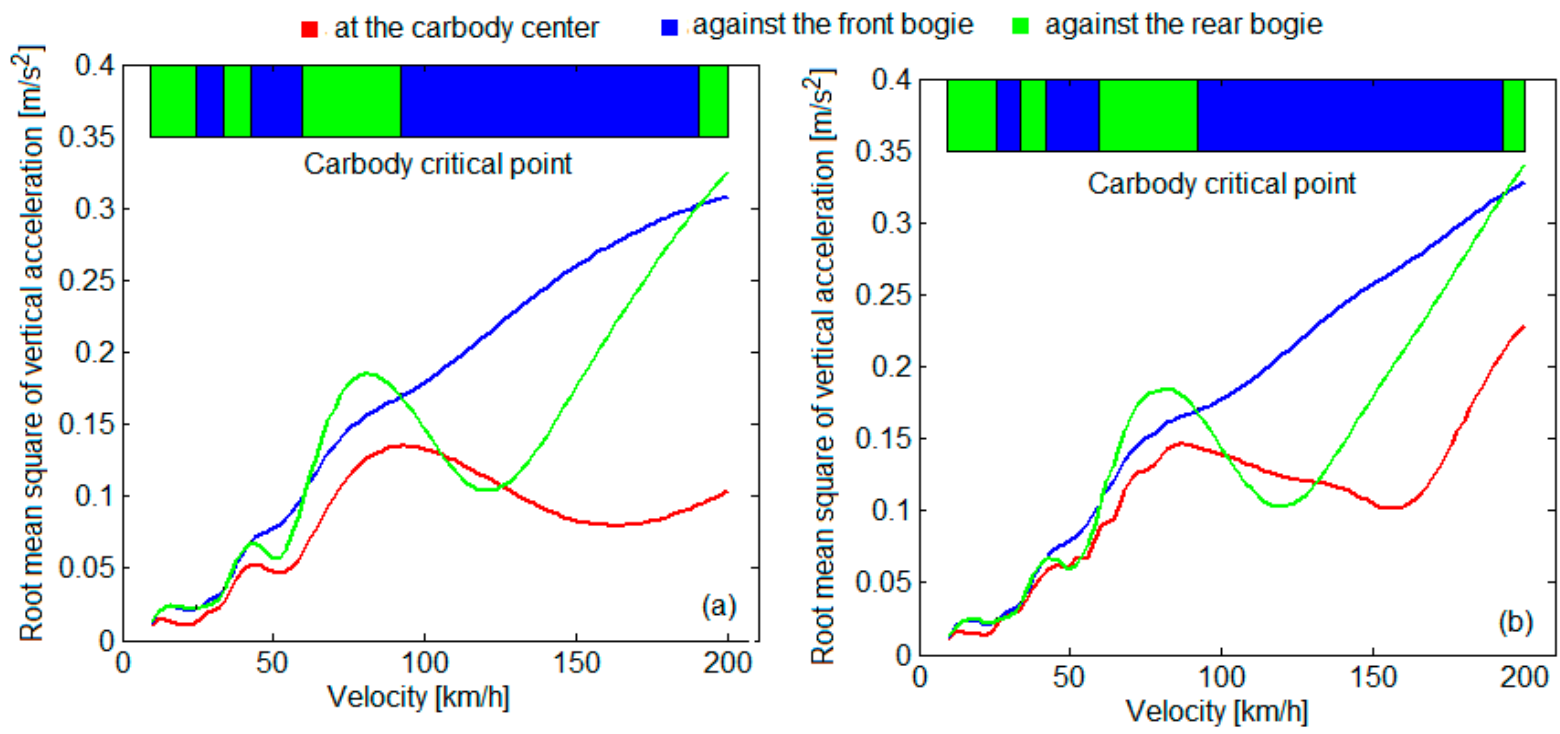

Figure 6. The position of the carbody critical point: (a) 'rigid carbody' model; (b) 'flexible carbody' model $\left(f_{v b}=6 \mathrm{~Hz}\right)$.

Figure 7 highlights the influence of the carbody vertical bending upon the root mean square of acceleration at a velocity of $200 \mathrm{~km} / \mathrm{h}$, in correlation with the damping ratio of the secondary suspension and defined according to the equation

$$
\zeta_{c}=\frac{4 c_{z c}}{2 \sqrt{4 k_{z c} m_{c}}}
$$



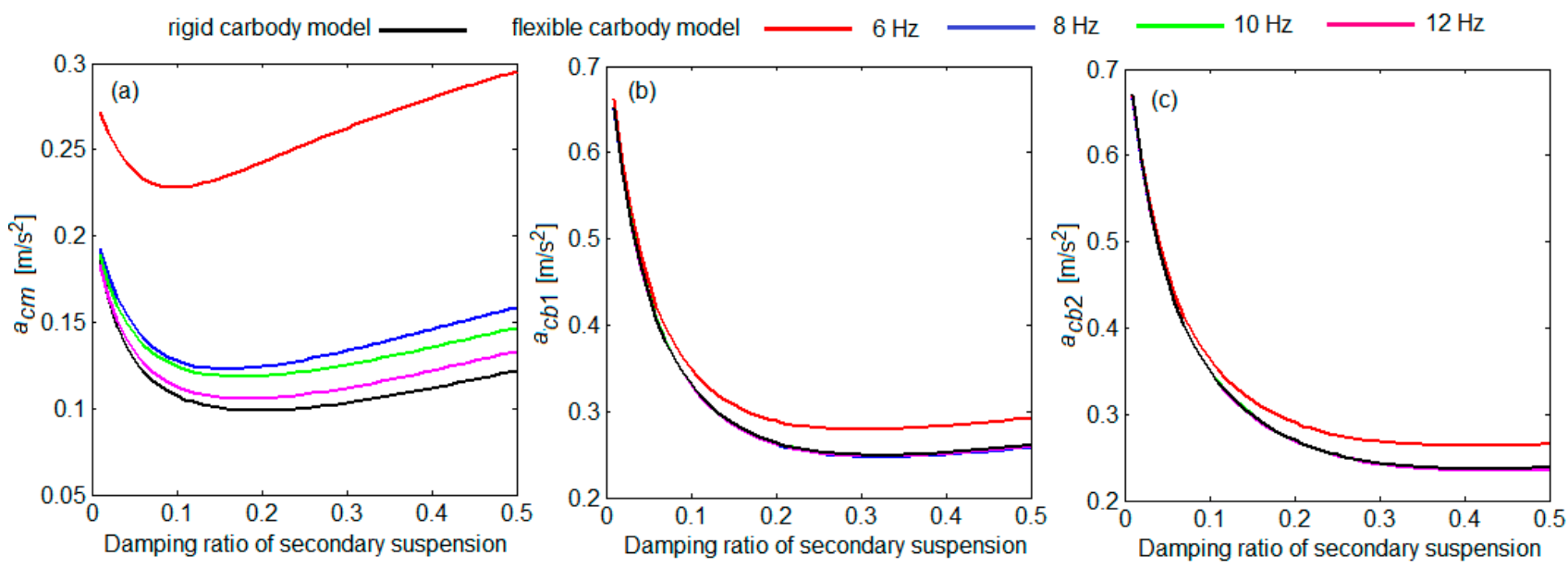

Figure 7. Influence of the carbody vertical bending upon the root mean square of acceleration in correlation with the damping ratio of secondary suspension: (a) at the carbody centre; (b) against the front bogie; (c) against the rear bogie.

In accordance with the reference parameters of the vehicle model (see Table 1), the reference value of the damping ratio of the secondary suspension is $\zeta_{c}=0.12$.

For both models, it is noticed that the root mean square of acceleration continuously decreases until it reaches a minimum value, while the damping ratio of the secondary suspension increases to a certain value. The minimum value of the root mean square of acceleration depends on the carbody reference point and then on the model type-the 'rigid carbody' model or the 'flexible carbody' model. In the case of the 'rigid carbody' model, the damping ratio that minimises the root mean square of acceleration at the carbody centre is 0.2 , while the root mean square of acceleration is minimum for $\zeta_{c}=0.32$ and $\zeta_{c}=0.43$, respectively (see Figure 8), above the bogies.

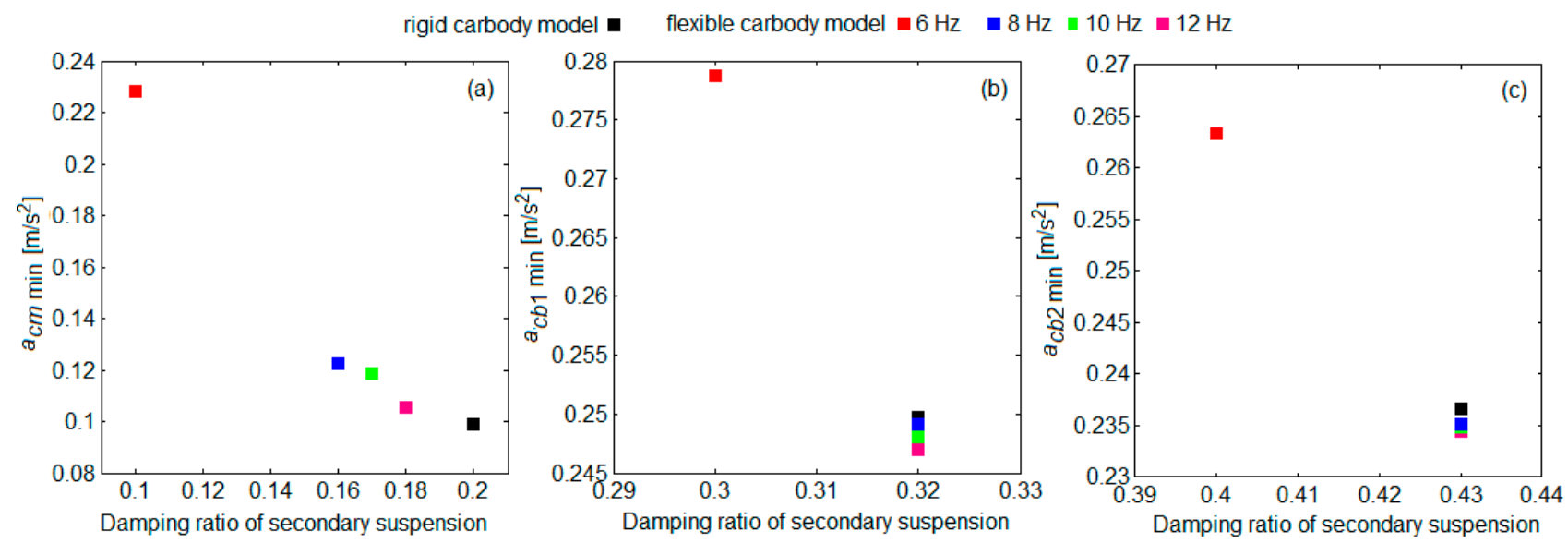

Figure 8. The damping ratio of secondary suspension minimizing the root mean square of acceleration: (a) at the carbody centre; (b) against the front bogie; (c) against the rear bogie.

The value of the damping ratio minimizing the root mean square of acceleration at the carbody centre declines for the flexible carbody (Figure 8, diagram a); the more flexible the carbody, the smaller this value (for instance, $\zeta_{c}=0.10$ for $f_{v b}=6 \mathrm{~Hz} ; \zeta_{c}=0.18$ for $f_{v b}=12 \mathrm{~Hz}$ ). In the points located above the two bogies, the value of the damping ratio that minimises the root mean square of acceleration coincides with the value identified for the rigid carbody, $\zeta_{c}=0.32$-above the front bogie, $\zeta_{c}=0.43$-above the rear bogie, for $f_{v b}=8 \mathrm{~Hz}, f_{v b}=10 \mathrm{~Hz}$ and $f_{v b}=12 \mathrm{~Hz}$ (Figure 8 , diagrams $\mathrm{b}$ and $\mathrm{c}$ ). For a very flexible carbody $\left(f_{v b}=6 \mathrm{~Hz}\right)$, the damping ratio that minimises the root mean square of acceleration is smaller, $\zeta_{c}=0.30$ and $\zeta_{c}=0.40$, respectively. 
The Figure 9 is used to analyse the influence of the carbody vertical bending upon the root mean square of acceleration at a velocity of $200 \mathrm{~km} / \mathrm{h}$, in correlation with the damping ratio of primary suspension. The damping ratio of primary suspension is calculated with the relation:

$$
\zeta_{b}=\frac{4 c_{z b}}{2 \sqrt{4 k_{z b} m_{b}}} .
$$

For the reference parameters of the vehicle model (see Table 1), the reference value of the damping ratio for the primary suspension is $\zeta_{b}=0.22$.
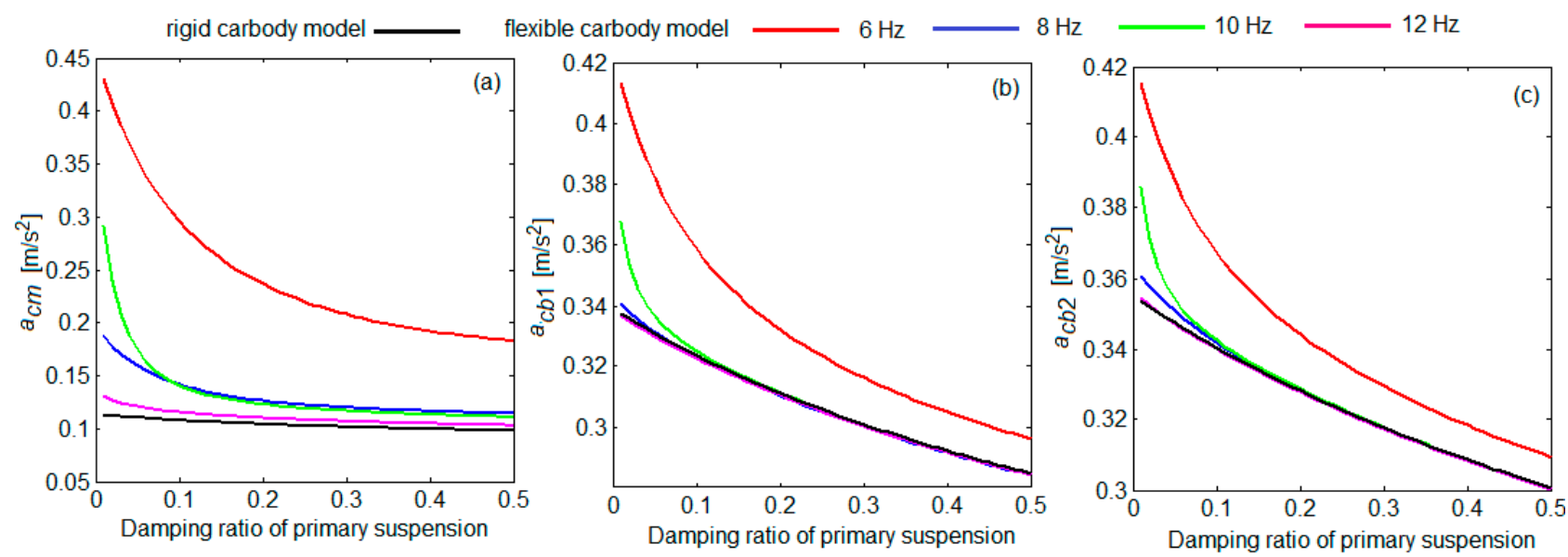

Figure 9. Influence of the carbody vertical bending upon the root mean square of acceleration in correlation with the damping ratio of primary suspension: (a) at the carbody centre; (b) against the front bogie; (c) against the rear bogie.

The results show that, for both models, the root mean square of acceleration continuously decreases with the increase of the damping of the primary suspension. The influence of the carbody vertical bending is visible in the decrease rate of the root mean square of acceleration, as shown in Figure 10.
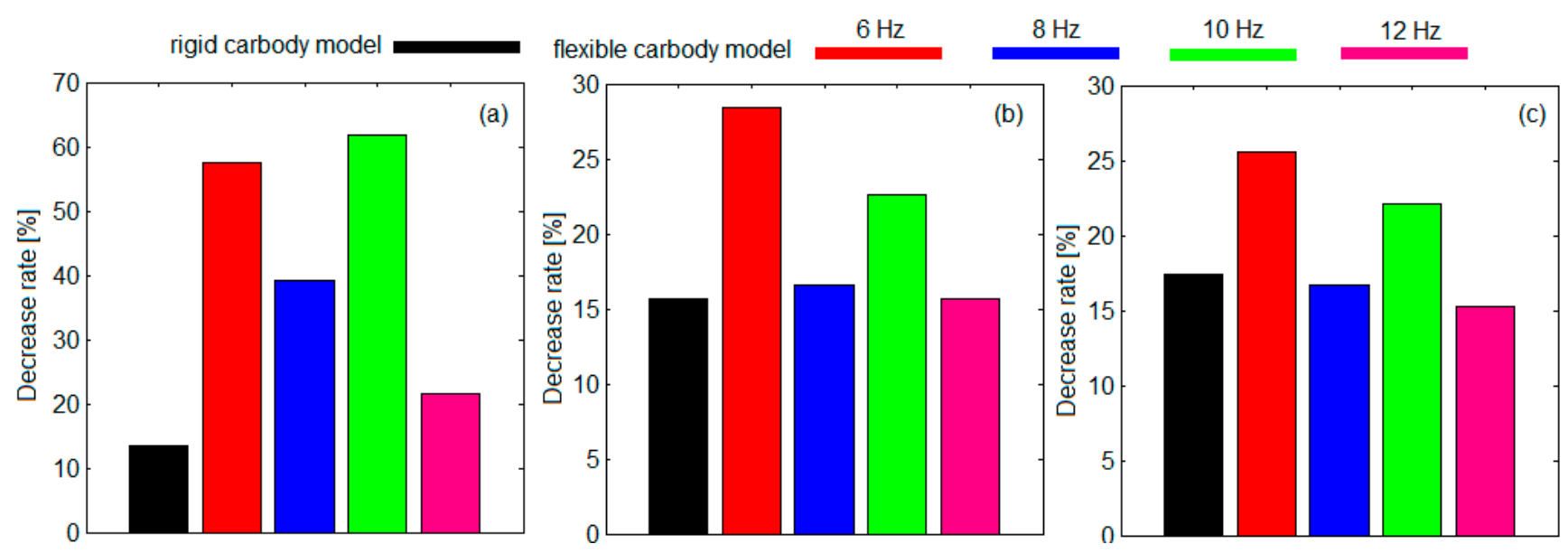

Figure 10. The decrease rate of the root mean square of acceleration with the damping ratio of primary suspension: (a) at the carbody centre; (b) against the front bogie; (c) against the rear bogie.

For the rigid carbody, the decrease rate of the root mean square of acceleration is higher above the two bogies than at the carbody centre. Instead, for the flexible carbody, the decrease rate of the root mean square of acceleration is higher at the carbody centre for any of the four situations being considered.

Comparing the results from the flexible carbody with those corresponding to the rigid carbody, the decrease rate of the root mean square of acceleration is observed to always be significantly higher for the flexible carbody at the carbody centre. Conversely, in 
the reference points of the carbody above the bogies, the decrease rates of the root mean square of acceleration for the flexible carbody can be close to or even lower than the ones corresponding to the rigid carbody (for $f_{v b}=8 \mathrm{~Hz}$ and $f_{v b}=12 \mathrm{~Hz}$ ).

\section{Conclusions}

This paper analyses the effects of the first vertical bending mode upon the vibration behaviour of the railway vehicle carbody. This is done by comparing the results from the numerical simulations developed based on a 'flexible carbody' vehicle model with the ones from the 'rigid carbody' model.

The basic characteristics of the vibration behaviour of the carbody for various carbody flexibilities have been analysed by means of the power spectral density of the vertical acceleration in three reference points of the carbody situated at the carbody centre and against the two bogies. The bending vibration has been shown to influence the vibration behaviour of the carbody, mainly at its centre and less against the two bogies. At the carbody centre, the contribution of this vibration mode is more important at high velocities, to the point when the power spectral density of the vertical acceleration dominates in the case of very flexible carbodies. In the carbody reference points above the bogies, the power spectral density of the vertical acceleration is dominated by the pitch vibration, the bending weight being very low, even for a high flexibility in the carbody.

To highlight the influence of the vertical bending upon the vibrations level in the carbody reference points, the values of the root mean square of vertical acceleration for the various flexibility of the carbody in the 'flexible carbody' model have been compared with the ones in the 'rigid carbody' model, in correlation with the velocity and the damping ratios of the two suspension stages of the vehicle.

The results correlated with the velocity have shown an important increase in the vibrations level at the carbody centre due to the bending vibrations in the range of high velocities. For the most adverse conditions-high flexibilities of the carbody and high velocities - the root mean square of acceleration is almost double the root mean square of acceleration in the rigid carbody. Still, based on the results correlated with the velocity, it has been shown the bending vibrations do not change the position of the critical point of the vibrations level of the carbody. Both for the 'rigid carbody' model and the 'flexible carbody' model, the critical point of the carbody is located above one of the bogies, and its position modifies as a function of velocity.

In accordance with the results correlated with the damping ratio of secondary suspension, the value of the damping ratio minimizing the root mean square of acceleration at the carbody centre has been proven to be lower for the flexible carbody than the rigid carbody. This value decreases along with the bending frequency of the carbody. In the points above the two bogies, the value of the damping ratio minimizing the root mean square of acceleration is the same for both models.

For both models, the results correlated with the damping ratio of primary suspension have showed that the level of vibrations continuously decreases with the increase of the damping of primary suspension, yet the influence of the carbody vertical bending is visible in the decrease rate of the root mean square of acceleration in the carbody reference points. In case of the rigid carbody, the decrease rate of the root mean square of acceleration is higher above the two bogies than at the carbody centre. Instead, for the flexible carbody, the decrease rate of the root mean square of acceleration is higher at the carbody centre.

Author Contributions: Conceptual approach, M.D.; methodology, M.D.; software, M.D. and I.I.D.; validation, M.D.; formal analysis, M.D. and I.I.D.; writing—original draft, M.D.; writing-review and editing, M.D. and I.I.D. Both authors have read and agreed to the published version of the manuscript.

Funding: This research received no external funding.

Institutional Review Board Statement: Not applicable.

Informed Consent Statement: Not applicable. 


\section{Data Availability Statement: Not applicable.}

Conflicts of Interest: The authors declare no conflict of interest.

\section{References}

1. Xu, L.; Zhai, W.; Gao, J.; Meacci, M.; Chen, X. On effects of track random irregularities on random vibrations of vehicle-track interactions. Probabilistic Eng. Mech. 2017, 50, 25-35. [CrossRef]

2. Zhai, W.; Wang, K.; Cai, C. Fundamentals of vehicle-track coupled dynamics. Veh. Syst. Dyn. 2009, 47, 1349-1376. [CrossRef]

3. Song, Y.; Wang, Z.; Liu, Z.; Wang, R. A spatial coupling model to study dynamic performance of pantograph-catenary with vehicle-track excitation. Mech. Syst. Signal Process. 2021, 151, 107336. [CrossRef]

4. Cheli, F.; Corradi, R. On rail vehicle vibrations induced by track unevenness: Analysis of the excitation mechanism. J. Sound Vib. 2011, 330, 3744-3765. [CrossRef]

5. Ágh, C. Comparative analysis of axlebox accelerations in correlation with track geometry irregularities. Acta Tech. Jaurinensis 2019, 12, 161-177. [CrossRef]

6. Dumitriu, M. Analysis of the dynamic response in the railway vehicles to the track vertical irregularities. Part I: The theoretical model and the vehicle response functions. J. Eng. Sci. Technol. Rev. 2015, 8, 24-31. [CrossRef]

7. Dumitriu, M.; Fologea, D. Numerical analysis on the correlation between bogie dynamic response and vertical track irregularities. UPB Sci. Bull. Ser. D Mech. Eng. 2019, 81,99-110.

8. Dumitriu, M.; Cruceanu, I.C. Effect of vertical track irregularities on the vibration of railway bogie. UPB Sci. Bull. Ser. D Mech. Eng. 2019, 81, 67-78.

9. Pombo, J.; Ambrósio, J. An alternative method to include track irregularities in railway vehicle dynamic analyses. Nonlinear Dyn. 2012, 68, 161-176. [CrossRef]

10. Shan, W.; Wu, P.; Wu, X.; Zhang, F.; Shi, H. Effect of wheel polygonization on the axle box vibrating and bolt self-loosening of high-speed trains. IOP Conf. Ser. J. Phys. Conf. Ser. 2019, 1213, 052044. [CrossRef]

11. Peng, B.; Iwnicki, S.; Shackletona, P.; Crosbee, D.; Zhao, Y. The influence of wheelset flexibility on polygonal wear of locomotive wheels. Wear 2019, 432-433, 102917. [CrossRef]

12. Mazilu, T.; Dumitriu, M.; Tudorache, C.; Sebesan, M. Wheel/rail interaction due to the polygonal wheel. UPB Sci. Bull. Ser. D Mech. Eng. 2011, 3, 95-108.

13. Mazilu, T. A dynamic model for the impact between the wheel flat and rail. UPB Sci. Bull. Ser. D Mech. Eng. 2007, 69, 45-58.

14. Mazilu, T. Geometric model of a railway wheel with irregular contour. Adv. Intell. Syst. Comput. 2016, 356, 155-166.

15. Tomioka, T.; Takigami, T.; Suzuki, Y. Numerical analysis of three-dimensional flexural vibration of railway vehicle car body. Vehicle Syst. Dyn. 2006, 44, 272-285. [CrossRef]

16. Yang, G.; Wang, C.; Xiang, F.; Xiao, S. Effect of train carbody's parameters on vertical bending stiffness performance. Chin. J. Mech. Eng. 2016, 29, 1120-1126. [CrossRef]

17. Dumitriu, M.; Stănică, D.I. Vertical bending vibration analysis of the car body of railway vehicle. IOP Conf. Ser. Mater. Sci. Eng. 2019, 564, 012104. [CrossRef]

18. Dumitriu, M.; Cruceanu, C. Influences of carbody vertical flexibility on ride comfort of railway vehicles. Arch. Mech. Eng. 2017, 64, 119-238. [CrossRef]

19. Shi, H.; Wu, P. Flexible vibration analysis for car body of high-speed EMU. J. Mech. Sci. Technol. 2016, 30, 55-66. [CrossRef]

20. Ye, H.; Zeng, J.; Wang, Q.; Han, X. Study on carbody flexible vibration considering layout of underneath equipment and doors. In Proceedings of the 4th International Conference on Sensors, Measurement and Intelligent Materials (ICSMIM 2015), Shenzhen, China, 27-28 December 2015; pp. 1177-1183.

21. Zhou, J.; Goodall, R.; Ren, L.; Zhang, H. Influences of car body vertical flexibility on ride quality of passenger railway vehicles. Proc. Inst. Mech. Eng. Part F J. Rail Rapid Transit 2009, 223, 461-471. [CrossRef]

22. Stănică, D.I.; Dumitriu, M. Critical points numerical analysis of ride comfort of the flexible railway carbody. IOP Conf. Ser. Mater. Sci. Eng. 2019, 682, 012007. [CrossRef]

23. Huang, C.; Zeng, J.; Luo, G.; Shi, H. Numerical and experimental studies on the car body flexible vibration reduction due to the effect of car body-mounted equipment. Proc. Inst. Mech. Eng. Part F J. Rail Rapid Transit 2018, 232, 3-13. [CrossRef]

24. Dumitriu, M. A new passive approach to reducing the carbody vertical bending vibration of railway vehicles. Veh. Syst. Dyn. 2017, 55, 1787-1806. [CrossRef]

25. Dumitriu, M.; Cruceanu, C. Approaches for reducing structural vibration of the carbody railway vehicles. In Proceedings of the MATEC Web of Conferences-IManE\&E 2017, Iasi, Romania, 24-27 May 2017; Volume 112, p. 07006.

26. Dumitriu, M. Ride comfort enhancement in railway vehicle by the reduction of the carbody structural flexural vibration. $I O P$ Conf. Ser. Mater. Sci. Eng. 2017, 227, 012042. [CrossRef]

27. Gong, D.; Zhou, J.; Sun, W.; Sun, Y.; Xia, Z. Method of multi-mode vibration control for the carbody of high-speed electric multiple unit trains. J. Sound Vib. 2017, 409, 94-111. [CrossRef]

28. Gong, D.; Zhou, J.; Sun, W. Passive control of railway vehicle car body flexural vibration by means of under frame dampers. J. Mech. Sci. Technol. 2017, 31, 555-564. [CrossRef]

29. Sun, Y.; Gong, D.; Zhou, J. Study on vibration reduction design of suspended equipment of high speed railway vehicles. J. Phys. Conf. Ser. 2016, 744, 012212. [CrossRef] 
30. Aida, K.Y.; Tomioka, T.; Takigami, T. Reduction of carbody flexural vibration by the high-damping elastic support of under-floor equipment. QR RTRI 2015, 56, 262-267. [CrossRef]

31. Shi, H.L.; Luo, R.; Wu, P.B. Application of DVA theory in vibration reduction of carbody with suspended equipment for high-speed EMU. Sci. China Technol. Sci. 2014, 57, 1425-1438. [CrossRef]

32. Tomioka, T. Reduction of car body elastic vibration using high-damping elastic supports for under-floor equipment. Railw. Technol. Avalanche 2012, 41, 245-270.

33. Sugahara, Y.; Watanabe, N.; Takigami, T.; Koganei, R. Vertical vibration suppression system for railway vehicles based on primary suspension damping control-system development and vehicle running test results. Q. Rep. RTRI 2011, 52, 13-19. [CrossRef]

34. Tomioka, T.; Takigami, T. Reduction of bending vibration in railway vehicle carbodies using carbody-bogie dynamic interaction. Veh. Syst. Dyn. 2010, 48, 467-486. [CrossRef]

35. Kamada, T.; Hiraizumi, T.; Nagai, M. Active vibration suppression of lightweight railway vehicle body by combined use of piezoelectric actuators and linear actuators. Veh. Syst. Dyn. 2010, 48, 73-87. [CrossRef]

36. Kamada, T.; Kiuchi, R.; Nagai, M. Suppression of railway vehicle vibration by shunt damping using stack type piezoelectric transducers. Veh. Syst. Dyn. 2008, 46, 561-570. [CrossRef]

37. Schandl, G.; Lugner, P.; Benatzky, C.; Kozek, M.; Stribersk, M. Comfort enhancement by an active vibration reduction system for a flexible railway car body. Veh. Syst. Dyn. 2007, 45, 835-847. [CrossRef]

38. Takigami, T.; Tomioka, T. Investigation to suppress bending vibration of railway vehicle carbodies using piezoelectric elements QR RTRI 2005, 46, 225-230. [CrossRef]

39. Kozek, M.; Benatzky, C.; Schirrer, A.; Stribersky, A. Vibration damping of a flexible car body structure using piezo-stack actuators. In Proceedings of the 17th World Congress the International Federation of Automatic Control, Seoul, Korea, 6-11 July 2008; pp. 8284-8292.

40. Schirrer, A.; Kozek, M. Co-simulation as effective method for flexible structure vibration control design validation and optimization. In Proceedings of the 16th Mediterranean Conference on Control and Automation Congress Centre, Ajaccio, France, 25-27 June 2008; pp. 481-486.

41. Dumitriu, M. On the critical points of vertical vibration in a railway vehicle. Arch. Mech. Eng. 2014, 61, 115-140. [CrossRef]

42. Dumitriu, M.; Crăciun, C. Modelling of structural flexibility of the carbody railway vehicles. In Proceedings of the MATEC Web of Conferences-IManE\&E 2017, Iasi, Romania, 24-27 May 2017; Volume 112, p. 07007.

43. C 116. Interaction between Vehicles and Track, RP 1, Power Spectral Density of Track Irregularities, Part 1: Definitions, Conventions and Available Data; UIC: Utrecht, The Netherlands, 1971.

44. Dumitriu, M. Analysis of the dynamic response in the railway vehicles to the track vertical irregularities. Part II: The numerical analysis. J. Eng. Sci. Technol. Rev. 2015, 8, 32-39. [CrossRef]

45. Gong, D.; Gu, Y.J.; Song, Y.J.; Zhou, J. Study on geometry filtering phenomenon and flexible car body resonant vibration of articulated trains. Adv. Mater. Res. 2013, 787, 542-547. [CrossRef]

46. Gong, D.; Zhou, J.; Sun, W.J. On the resonant vibration of a flexible railway car body and its suppression with a dynamic vibration absorber. J. Vib. Control 2013, 19, 649-657. [CrossRef]

47. Zhou, J.; Wenjing, S. Analysis on geometric filtering phenomenon and flexible car body resonant vibration of railway vehicles. J. Tongji Univ. 2009, 37, 1653-1657. 